\title{
Family-Centered Care: An Evolutionary Concept Analysis
}

\author{
Seyed Tayeb Moradian ${ }^{{ }^{*}}$ \\ ${ }^{1}$ Atherosclerosis Research Center, Baqiyatallah University of Medical Sciences, Tehran, Iran
}

Corresponding Author: Seyed Tayeb Moradian, PhD, Assistant Professor, Atherosclerosis Research Center, Baqiyatallah University of Medical Sciences, Tehran, Iran. Tel: +98-9123781448, Email: t.moradyan@yahoo.com

Received March 4, 2018; Accepted May 20, 2018; Online Published June 25, 2018

\begin{abstract}
Introduction: The inappropriate development of nursing concepts is one of the most important obstacles to the progress of nursing knowledge. Family-centered care is one concept that is not well-defined, even though it is widely used in many areas of nursing and caregiving. This study aimed to analyze the concept of family-centered care using Rodgers' evolutionary model.

Methods: The 8 steps of Rodgers' evolutionary model were followed. After concept selection, the Pubmed, Medline, Scopus, Science Direct, OVID, and SID databases were seached for the terms "family-centered care", "parental involvement", "family participation", and "care by families".

Results: The results of this study, including the dimensions, antecedents, barriers, and consequences, are reported based on Rodgers' model. Family-centered care is described as a holistic point of view, a philosophy that helps families in their caring role, the basic principles of child care, care given by parents, parents and professionals working together, and the chance for parents to protect their children under the supervision of professionals. In this study the antecedents of family-centered care were categorized as being politicalconceptual, economical, and motivational. Some results of family-centered care are improved patient and family satisfaction, increased efficacy and improved quality of life, improved flow of information, and better interaction between the family and the professional team. Conclusions: Data from the present study showed that even though family-centered care is an appropriate framework for the provision of health services, more study is needed for better implementation.

Keywords: Family-Centered Nursing, Nursing, Care, Participation

Citation: Moradian ST. Family-centered care: an evolutionary concept analysis. Int J Med Rev. 2018;5(2):82-86. doi:10.29252/JJMR-050207.
\end{abstract}

\section{Introduction}

The lack of proper development of nursing concepts is one of the most important barriers to the continued development of nursing knowledge. Identifying and clarifying nursing concepts not only leads to descriptions and definitions, but also promotes the development of nursing theories. ${ }^{1,2}$ Discussing nursing concepts aids in their sensible use. Concept analysis not only provides meanings, but also explains how these meanings are expanded..$^{2-4}$

In the last century, revolutionary changes have occurred in many political, social, and economic arenas of human life, and the health system is no exception. Its vision has changed from disease-centered to patient- and family-centered healthcare. As an example, the year 1994 was introduced by the United Nations as the International Year of the Family. Scientific publications in the field of family-centered healthcare have led to increased public awareness. ${ }^{5}$

History of the Concept of Family-Centered Care The year 1940 was the starting point for family-centered care. Rodgers' work some years later initiated patient-centered care in the field of psychology and introduced it as a continuous process. In this approach, therapists treat patients as a person with rights and importance and respect the rights and abilities of patients to guide their own treatment.

In 1959, Rodgers presented a diagram for the therapeutic relationship of family and society focused on the relationship and two-way effect of the treatment process, family changes, and participation and individual performance in social life. ${ }^{6}$ In 1960, Rodgers' idea was adopted in hospitals. Patientcentered care became family-centric, because the family plays an important role in the treatment of the child. ${ }^{7}$ In 1986, families were legally entitled to participate in the treatment of their children in a role equal to that of the professional healthcare staff. ${ }^{8}$ At present, the family is a part of a patient's healthcare team. Family participation in decision-making in the past 20 years has increased..$^{9}$ Clarifying the importance of treating patients in the family has led to a change in vision from patient-centered care to the family-centered care for adults. The general understanding of the family as the most important educator, facilitator, and supporter has improved. ${ }^{5,9}$ In recent years, this concept has evolved and is now widely used. It is said to be applicable in all therapeutic areas, for patients of all ages, and in all environments. Some experts

Copyright (C) 2018 The Author(s). This is an open-access article distributed under the terms of the Creative Commons Attribution License (http:// creativecommons.org/licenses/by/4.0), which permits unrestricted use, distribution, and reproduction in any medium, provided the original work is properly cited. 
recommend this method as the best available practice. Given the widespread use of the concept and the evolving situation of healthcare systems, the present study aimed to clarify the concept of family-centered care. ${ }^{10}$

\section{Methods}

Rodgers' evolutionary model has 8 steps. In this section, each of these steps and the work done in this study is briefly explained. In addition, some of the steps are merged. The steps are as follows:

1. Identifying the concept of interest

2. Identifying and selecting an appropriate sample and setting

3. Collecting data relevant to identifying attributes and the contextual basis

4. Analyzing the data

5. Identifying an exemplar of the concept

6. Identifying implications and hypotheses ${ }^{1}$

\section{Finding the Concept}

First, the concept is selected. The benefit of communication and application of the concept of family-based care for childcare has already been proven. ${ }^{7}$ In recent years, familycentered care has been accepted as a philosophy and foundation for treatment and care in all parts and conditions, but a literature review suggested that recent articles have only emphasized that this philosophy can also be used in adults. ${ }^{11,12}$ Research has been done on various disciplines in this field..$^{13,14}$ Healthcare workers have much difficulty with this concept in practice. ${ }^{9,15}$ Basic questions like how to provide essential information to the family; how to put aside specialized knowledge and just be a contributor; and when family members should be guided and when they should just listen remain unanswered. In addition, the use of the concept of family-centered care has not yet been clarified, not in the context of childcare, nor in other settings. There is insufficient evidence as to how family-centered care improves the outcome of the child and the family. ${ }^{16}$ Therefore, considering that one problem is in the application of this concept, the evolutionary method is a suitable method for concept analysis. ${ }^{2}$

Contrary to the philosophy of essentialism, the concept being analyzed is dynamical and varies over time.,17 The evolutionary approach for the concept of family-based care is appropriate, because there is some evidence that has evolved over time and has changed with changes in the care environment. ${ }^{3,18}$

Sample Selection, Resource Review and Data Analysis Rodgers mentioned the need to search extensively for resources. In this study, the keywords "family-centered care", "parental involvement", "family participation", and "care by family member" were used in searches on PubMed, Medline, Scopus, Science Direct, OVID, and SID databases. Public databases such as Google Scholar were also reviewed. Given the fact that the concept has a short, 40-year history, no attempt to limit the searches by time were made.
Articles retrieved from the searches were first generally examined in relation to the topic. Then, the articles that were determined to be relevant were assessed, and all data related to the properties of the concept, the antecedents, and the consequences were recorded on separate sheets. Most of the articles referred to Shelton's work in 1995, whose study seemed to provide a new area for family-centered care. Shelton provided a comprehensive framework for providing family-centered care to children. This framework has been used by parents of children with special educational needs and by others for children with chronic or critical illness. ${ }^{19}$

In this framework, community-based care is considered as a philosophy. When families and members of the treatment team are present, the normalized patterns of life are determined for the family. However, more research is needed to translate Shelton's framework into certain types of clinical practice. The researchers have emphasized that investigations into why it is difficult to implement family-centered care in acute conditions is needed. This framework is suitable for the care of a particular group of children with specific needs and is not transferable to other conditions. Given the different types of family-centered evolution in different countries and situations, it seems that Shelton's model does not apply to all working conditions.

\section{Results}

Family-Centered Care Dimensions

After collecting articles, the focus turned to identifying the essence of the concept using its properties. The properties of a concept were not definitions in dictionary, but their actual application. ${ }^{1}$ At this stage, the main features of the concept were extracted from the available resources. The search in resources and articles identified particular dimensions shared by all family-centered care policies, as follows:

1. Families are experts about what helps them and what damages them;

2. Families are valuable partners for policymakers who help them;

3. Families are not dependent upon treatment, but they are contributing and empowering it;

4. Family-centered policies and practices promote family and community-based systems and provide bipartite support; and

5. The principles of democracy and gender equality are respected in these policies. ${ }^{10}$

Mackean gave a rich overview of the key concepts of familycentered care that focused on:

1. Considering the family as the central element and the main source of strength and support;

2. Heeding the uniqueness and diversity of families and children;

3. Considering that parents are professional care providers;

4. Considering that family-based care is an enhancement of capabilities and not focusing on weaknesses;

5. Encouraging the partnership between the family and the treatment team; and 
6. Facilitating families in supporting each other and creating a supportive network. ${ }^{15}$

In most studies, care has been identified as the main element of family-centered care. ${ }^{10,15,20}$ The definition of family-centered care was also extracted from the studies. Some have defined family-centered care as a holistic perspective, a philosophy that helps families care for their children, the basic principle of child care, parental care, parenting, and professional cooperation, and a chance for parents to care for their children under the supervision of professionals. Others have defined it as the contribution of the family to a care plan, a partnership that assists the family as a primary care provider.

Based on the available definitions, family-centered care has two basic dimensions. One is more general and defines a context which is collaborative with the family. In this perspective, the nurse is a contributor and facilitator of care. The other is more functional and less participatory. In this perspective, the nurse plays the role of a concierge; s/he is the dominant actor in the partnership and decides what care is provided by the parent and what care is provided by the nurse. ${ }^{20}$ This view was mostly focused on intensive care units, which provide specialized care. It seems that families are not able to carry out such advanced care, so their participation covered the simple care of patients and specialized work was performed by the nurse. ${ }^{21}$ Occasionally, the presence of nurses is likely to restrict parental care. Both models suggest ways to gain family control on conditions such as strong communication, family involvement, and participation in family-centered care. ${ }^{20}$

\section{Discussion}

Antecedents and Consequences

Rodgers stressed that a review of resources could lead to the clarification of the antecedents and consequences which could contribute to the clarification of the concept. ${ }^{2}$ It seems that the presence of parents in the ward and their willingness to engage in childcare are the most important factors in accelerating family-centered care. In this study, based on the framework provided by Hutchfield, the antecedents were generally categorized as political-conceptual, economical, and motivational. ${ }^{20}$

\section{Consequences of Family-Centered Care}

It seems that this concept is not well accepted in adult care, and multiple barriers to its implementation exist. Based on the resources, however, the results indicate that family-centered care benefits both the child and the family.

Improving family and patient satisfaction, ${ }^{22}$ increasing self-efficacy, improving quality of life,,$^{23,24}$ improving the information flow and interactions between families and treatment professionals, ${ }^{25}$ helping intensive care patients to be aware of the care process, giving them relaxation and a sense of security, ${ }^{26}$ improving communication between patient and family, achieving improved treatment outcomes, ${ }^{27-29}$ acquiring a sense of re-control in family management, ${ }^{30}$ reducing nursing job burnout, ${ }^{31}$ creating a more effective relationship, increasing holistic nursing, ${ }^{18,32}$ and reducing depression and fatigue among caregivers, ${ }^{13,33,34}$ are the results extracted from studies on family-centered healthcare.

Although these conditions seem to improve the outcomes of the child and the family, research has shown that childcare in the family may be stressful. ${ }^{35-37}$ Thus, it is necessary to provide families with adequate support. ${ }^{16}$

\section{Model Case and Contrary}

Rodgers believed that the next stage of the process is identifying the model, borderline and contrary cases to help further identify the concept properties. Rodgers emphasized that pinpointing samples from personal experience is a good way to identify the essence of a concept. Parents who help provide physical or technical care represent a model case. Their involvement was voluntary, and efforts were made to promote and maintain the role of the family and its relationships. Moreover, parents' knowledge of their children was respected, and information was shared effectively. ${ }^{20}$

\section{Related Concepts}

The available resources indicated that parental participation, participatory care, participation and relationship with parents are the concepts related to family-centered care. In the analysis carried out by Nethercott, a difference was detected between parental involvement and parental participation. In parental involvement, the nurse usually supervises parental activity; in participation, parents are more involved and nursing is less supervised. ${ }^{38}$

\section{Application of the Concept and Further Research}

According to the review, family-centered care can be considered as a philosophy in providing care. It is applicable in all treatment areas and for all age groups. This concept has been taken from childcare and has been used in the care of adults. The review further showed that this concept is not welldefined in adults; further studies on this concept are needed. Some dimensions of the concept are not well defined. For example, it is not clear what cooperation and partnership is or how it works. ${ }^{39,40}$ It is also unclear which families can provide family-centered care or how much they can contribute to it.

Some questions about this treatment approach remain. Is this approach similarly effective in all areas of treatment and for patients with different diagnoses or do differences exist? In what areas can family involvement be used? Can all the work or only special tasks be done by the family or family members?

In cases of acutely ill patients, the presence of family can intervene in or even prevent the continuation of treatment. For example, patients undergoing cardio-pulmonary resuscitation, the presence of family members may prevent the normal course of treatment. Such situations require more detailed assessment. Although this method is recommended as a suitable framework for the provision of healthcare, it is necessary to clarify its more obscure points for ease of use.

\section{Conclusions}

The results of the current study showed that family-centered 
care is an appropriate framework for the provision of health services. In recent years, this approach has been used in all environments, especially intensive care units, with promising results. Nevertheless, some points still require further studies for this approach to be effectively implemented.

\section{Conflict of Interest Disclosures}

The author declares that there is no conflict of interest.

\section{References}

1. Rodgers BL, Knafl KA. Concept Development in Nursing: Foundations, Technqiues, and Applications. 2nd ed. Philadelphia: Saunders; 2000.

2. Rodgers BL. Concept analysis: an evolutionary view. In: Rodgers BL, Knafl KA, eds. Concept Development in Nursing: Foundations, Technqiues, and Applications. Philadelphia: Saunders; 1993.

3. Bradley SF. Processes in the creation and diffusion of nursing knowledge: an examination of the developing concept of family-centred care. J Adv Nurs. 1996;23(4):722-727. doi:10.1111/j.1365-2648.1996.tb00043.x.

4. Walker LO, Avant KC. Strategies for theory construction in nursing. 3rd ed. Norwalk: Appleton \& Lange; 1995.

5. Briar-Lawson K, Lawson HA. Family-centered Policies and Practices: International Implications. Columbia University Press; 2010.

6. Wexler DA, Rice LN. Innovations in client-centered therapy. Oxford, England: John Wiley \& Sons; 1974.

7. Rosenbaum P, King S, Law M, King G, Evans J. Family-centred service: A conceptual framework and research review. Phys Occup Ther Pediatr. 1998;18(1):1-20. doi:10.1080/J006v18n01_01.

8. Dyke P, Buttigieg P, Blackmore AM, Ghose A. Use of the measure of process of care for families (MPOC-56) and service providers (MPOC-SP) to evaluate family-centred services in a paediatric disability setting. Child Care Health Dev. 2006;32(2):167-176. doi:10.1111/j.1365-2214.2006.00604.x.

9. Leiter V. Dilemmas in sharing care: maternal provision of professionally driven therapy for children with disabilities. Soc Sci Med. 2004;58(4):837-849. doi:10.1016/S0277-9536(03)00258-2.

10. Bamm EL, Rosenbaum P. Family-centered theory: origins, development, barriers, and supports to implementation in rehabilitation medicine. Arch Phys Med Rehabil. 2008;89(8):16181624. doi:10.1016/j.apmr.2007.12.034.

11. Janzen W. Long-term care for older adults. The role of the family. J Gerontol Nurs. 2001;27(2):36-43; quiz 54-35. doi:10.3928/00989134-20010201-13.

12. Johnson BH. Family-centered care: Four decades of progress. Fam Syst Health. 2000;18(2):137-156. doi:10.1037/h0091843.

13. King RB, Semik PE. Stroke caregiving: difficult times, resource use, and needs during the first 2 years. J Gerontol Nurs. 2006;32(4):3744.

14. Schoot T, Proot I, ter Meulen R, de Witte L. Recognition of client values as a basis for tailored care: the view of Dutch expert patients and family caregivers. Scand J Caring Sci. 2005;19(2):169-176. doi:10.1111/j.1471-6712.2005.00327.x.

15. MacKean GL, Thurston WE, Scott CM. Bridging the divide between families and health professionals' perspectives on family-centred care. Health Expect. 2005;8(1):74-85. doi:10.1111/j.13697625.2005.00319.x.

16. Foster M, Whitehead L, Maybee P. Parents' and health professionals' perceptions of family centred care for children in hospital, in developed and developing countries: a review of the literature. Int J Nurs Stud. 2010;47(9):1184-1193. doi:10.1016/j. ijnurstu.2010.05.005

17. Rodgers BL. Philosophical foundations of concept development. In: Concept Development in Nursing: Foundations, Technqiues, and Applications. 2nd ed. Philadelphia: Saunders; 2000.
18. Mitchell ML, Chaboyer W. Family Centred Care--a way to connect patients, families and nurses in critical care: a qualitative study using telephone interviews. Intensive Crit Care Nurs. 2010;26(3):154-160. doi:10.1016/j.iccn.2010.03.003.

19. Shelton TL, Stepanek JS. Excerpts from family-centered care for children needing specialized health and developmental services. Pediatr Nurs. 1995;21(4):362-364.

20. Hutchfield K. Family-centred care: a concept analysis. J Adv Nurs. 1999;29(5):1178-1187. doi:10.1046/j.1365-2648.1999.00987.x.

21. Mitchell M, Chaboyer W, Burmeister E, Foster M. Positive effects of a nursing intervention on family-centered care in adult critical care. Am J Crit Care. 2009;18(6):543-552; quiz 553. doi:10.4037/ ajcc2009226.

22. Dowling J, Vender J, Guilianelli S, Wang B. A model of familycentered care and satisfaction predictors: the Critical Care Family Assistance Program. Chest. 2005;128(3 Suppl):81s-92s. doi:10.1378/chest.128.3_suppl.81S.

23. Masoodi R, Alhani F, Rabiei L, et al. The effect of family-centered empowerment model on quality of life and self efficacy of multiple sclerosis patients family care givers. Iranian Journal of Nursing Research. 2012;7(27):32-43.

24. Vahedian Azimi A, Alhani F, Ahmadi F, Kazemnejad A. The effect of family-centered empowerment model on the life style of myocardial infarction patients. Iranian Journal of Critical Care Nursing. 2010;2(4):127-32.

25. Zeinali J, Mirhaghjou SN, Mirzaei M, Alhani F, Kazemnezhad E, Dehghani M. The effect of family centered care on meeting parental information needs of hospitalized children. J Holist Nurs Midwifery. 2012;22(1):30-37.

26. Eldredge D. Helping at the bedside: Spouses' preferences for helping critically ill patients. Res Nurs Health. 2004;27(5):307321. doi:10.1002/nur.20033.

27. Lolaty HA, Bagheri-Nesami M, Shorofi SA, Golzarodi T, Charati JY. The effects of family-friend visits on anxiety, physiological indices and well-being of $\mathrm{MI}$ patients admitted to a coronary care unit. Complement Ther Clin Pract. 2014;20(3):147-151. doi:10.1016/j. ctcp.2014.03.002.

28. Peyrot M, Burns KK, Davies M, et al. Diabetes Attitudes Wishes and Needs 2 (DAWN2): a multinational, multi-stakeholder study of psychosocial issues in diabetes and person-centred diabetes care. Diabetes Res Clin Pract. 2013;99(2):174-184. doi:10.1016/j. diabres.2012.11.016.

29. Safaeepour L, Mokhtari Nouri J, Moradian ST, Saied Ghazis SM. The Effect of Family-Centered Care on the Duration of Weaning from Mechanical Ventilation in Coronary Artery Bypass Surgery Patients: A Clinical Trial Study. Iranian Journal of Critical Care Nursing. 2017;10(2):e10655. doi:10.5812/ccn.10655.

30. Arockiasamy V, Holsti L, Albersheim S. Fathers' experiences in the neonatal intensive care unit: a search for control. Pediatrics. 2008;121(2):e215-222. doi:10.1542/peds.2007-1005.

31. Geller G, Bernhardt BA, Carrese J, Rushton $\mathrm{CH}$, Kolodner $\mathrm{K}$. What do clinicians derive from partnering with their patients? A reliable and valid measure of "personal meaning in patient care". Patient Educ Couns. 2008;72(2):293-300. doi:10.1016/j. pec.2008.03.025.

32. Johnson BH, Abraham MR, Shelton TL. Patient- and familycentered care: partnerships for quality and safety. N C Med J. 2009;70(2):125-130.

33. Epstein RM. Making communication research matter: what do patients notice, what do patients want, and what do patients need? Patient Educ Couns. 2006;60(3):272-278. doi:10.1016/j. pec.2005.11.003.

34. Pryzby BJ. Effects of nurse caring behaviours on family stress responses in critical care. Intensive Crit Care Nurs. 2005;21(1):1623. doi:10.1016/j.iccn.2004.06.008.

35. Azoulay E, Pochard F, Kentish-Barnes N, et al. Risk of posttraumatic stress symptoms in family members of intensive care unit patients. Am J Respir Crit Care Med. 2005;171(9):987-994. 
doi:10.1164/rccm.200409-1295OC.

36. Chaboyer W, Kendall E, Kendall M, Foster M. Transfer out of intensive care: a qualitative exploration of patient and family perceptions. Aust Crit Care. 2005;18(4):138-141, 143-135. doi:10.1016/S1036-7314(05)80026-8.

37. Mitchell ML, Courtney M, Coyer F. Understanding uncertainty and minimizing families' anxiety at the time of transfer from intensive care. Nurs Health Sci. 2003;5(3):207-217. doi:10.1046/j.14422018.2003.00155.x.
38. Nethercott S. A concept for all the family. Family centred care: a concept analysis. Prof Nurse. 1993;8(12):794-797.

39. Litchfield R, MacDougall C. Professional issues for physiotherapists in family-centred and community-based settings. Aust J Physiother. 2002;48(2):105-112.doi:10.1016/S0004-9514(14)60204-X.

40. Morris R, Payne O, Lambert A. Patient, carer and staff experience of a hospital-based stroke service. Int J Qual Health Care. 2007;19(2):105-112. doi:10.1093/intqhe/mzl073. 